Original article

\title{
Association between high pre-pregnancy body mass index and antenatal depression: A study among pregnant women of upper socio-economic strata in North-West Delhi, India
}

\author{
Priyanka Arora, Bani Tamber Aeri " \\ Department of Food and Nutrition, Institute of Home Economics, Delhi University, F-4, Hauz Khas Enclave, New Delhi, India
}

\section{A R T I C L E I N F O}

\section{Keywords:}

Antenatal depression

Body mass index

Edinburgh postnatal depression scale

Pregnant women

India

\begin{abstract}
A B S T R A C T
Background: Magnitude of antenatal depression (AD) remains underexplored especially in the Indian population despite the growing body of research regarding the benefits of healthy pregnancy. Further, National Family Health Survey (NFHS- 3 and NFHS-4) data indicate that there is an escalating rise in the proportion of overweight/obese women of reproductive age from $26.4 \%$ to $34.9 \%$ residing in Delhi. Synergistic impact of high prepregnancy weight and AD can adversely affect obstetric outcome. Hence, the present study aimed to assess and compare the prevalence of $\mathrm{AD}$ among normal weight, overweight and obese pregnant women.

Methods: Present data is a part of an ongoing longitudinal study among pregnant women belonging to upper socio-economic strata residing in Delhi, India. A total of 186 subjects attending private antenatal clinics in NorthWest Delhi were enrolled at $\leq 16$ week of gestation. The subjects were screened for AD using Edinburgh Postnatal Depression Scale, regularly at baseline ( $\leq 16$ th week), midterm (18th-20th week) and end-line ( $\geq 32$ nd week) of their pregnancies. Additional socio-demographic characteristics, anthropometric measurements and obstetric history were recorded and analysed using SPSS (Statistical Package for Social Sciences) version 25.

Results: More than one-third of subjects screened positive for depression throughout pregnancy. Prevalence of AD was highest among obese subjects $(50 \%, 48.3 \%, 51 \%)$ as compared to normal weight $(36.7 \%, 30.4 \%, 37.5 \%)$ and overweight $(27.6 \%, 32 \%, 29.2 \%)$ subjects during baseline, midterm and end-line respectively.

Conclusion: Prevalence of AD was high irrespective of weight category. Obese women were likely to have more symptoms of depression compared to normal weight and overweight women throughout pregnancy. A holistic approach needs to be adopted by health care professionals including regular screening of $\mathrm{AD}$ and provide healthy lifestyle related advice to pregnant women.
\end{abstract}

\section{Introduction}

The prevalence of overweight/obesity is rising globally as well as in India. According to the National Family Health Survey-4 (NFHS, 201516), a rise has been observed from $12.6 \%$ (NFHS-3, 2005-06) to $20.7 \%$ among overweight/obese (Body Mass Index- $\geq 25 \mathrm{~kg} / \mathrm{m}^{2}$ ) reproductive age women residing in India (NFHS-4). In Delhi, percentage of overweight/obese women in the reproductive age has escalated from $26.4 \%$ (National Family Health Survey, NFHS-3, 2005-06) to $34.9 \%$ (NFHS-4, 2015-16). ${ }^{1,2}$ The health risks associated with higher pre-pregnancy body mass index (BMI) i.e. Gestational diabetes mellitus (GDM), gestational hypertension (GHTN) and preeclampsia are well established. ${ }^{3,4}$ In addition, overweight/obesity, as well as excessive weight gain during pregnancy, are independent explanatory variables for fetal birth weight and are well recognised independent risk factors for giving birth to large for gestational age (LGA) infants. ${ }^{5,6}$ But the relationship between overweight/obesity and maternal mental health is still neglected.

According to the National Mental Health Survey (NMHS)-2016, one in every ten persons in India suffers from depression and anxiety and $20 \%$ of these depressed Indians are pregnant women and new mothers. ${ }^{7}$ Women during pregnancy tend to experience several physiological, hormonal and psychological changes which can increase the likelihood of mental and emotional changes resulting in depression, anxiety or psychological distress among them. ${ }^{8}$ The prevalence rate of antenatal Depression (AD) differs between High, Middle and Low-Income

\footnotetext{
* Corresponding author.

E-mail addresses: Priyanka.512019@gmail.com (P. Arora), bani.aeri@ihe.du.ac.in (B.T. Aeri).
} 
countries. The prevalence rate is observed to be lower in high income countries like Hong Kong (4.4\%), ${ }^{9}$ Australia $(7 \%)^{10}$ and Finland $(7.7 \%)^{11}$ whereas higher prevalence has been reported in Lower-Middle Income countries like Bangladesh $(18 \%),{ }^{12}$ Ethiopia $(24.9 \%)^{13}$ and Pakistan (64.6\%). ${ }^{14}$ According to studies, prevalence of AD in India varies from $9.18 \%$ to $36.7 \% .{ }^{15,16}$ However, worldwide, psychological health among women with higher pre-pregnancy BMI has been poorly studied. ${ }^{17}$ In 2013, a systematic review and meta-analysis ${ }^{18}$ was conducted which reported that women who were obese, when they became pregnant were more likely to experience $\mathrm{AD}$ than women with normal weight (OR 1.43, $95 \%$ CI 1.27-1.61). Similarly, another review ${ }^{19}$ stated the association between high pre-pregnancy $\mathrm{BMI}$ and symptoms of $\mathrm{AD}$ to be significant after adjusting for socio-demographic factor. Reportedly, $\mathrm{AD}$ represents a risk factor for adverse birth outcomes such as preterm birth ( $<37$ weeks of gestation), low birth weight $(<2500 \mathrm{~g})$, small-for-gestational age $\mathrm{a}^{20,21}$ and poorer behavioral, neuro-physiological and cognitive development of the child. ${ }^{22,23}$ Further, there is also increase in empirical evidence that maternal depression when left untreated during pregnancy tend to have potential sequelae which can persist beyond perinatal period. ${ }^{24}$ Thus, overweight/obese women who experience $\mathrm{AD}$ are at a higher risk for poor feto-maternal outcome.

In comparison to the western countries, in the Indian settings the relationship between perinatal depression and pre-pregnancy BMI is underexplored. Since obesity and depression are often comorbid, ${ }^{25}$ it is interesting to elucidate the relation of prenatal depression among Indian women, in association with their weight status. In the current study, an effort has been made to compare the prevalence and pattern of $\mathrm{AD}$ across three different time-points during pregnancy (baseline: $\leq 16$ th week, midterm:18th-20th week and end-line: $\geq 32$ nd week of pregnancy) among normal weight and higher pre-pregnancy BMI category subjects belonging to upper socio-economic status (SES) residing in North-West Delhi, India.

\section{Materials and methods}

\subsection{Study design and setting}

The present observational study is a part of another ongoing longitudinal study which is being conducted among pregnant women, attending private antenatal clinics in North-West district of Delhi, India which were selected owing to accessibility and ease of obtaining permission for conducting study from the concerned authorities. All women attending the selected antenatal clinics with confirmed pregnancy of $\leq 16$ th week, belonging to upper SES and were willing to participate were recruited in the study purposively and categorized into three groups: normal weight, overweight and obese as per their prepregnancy BMI. Women above 40 years of age, physically challenged and cognitive impaired (epilepsy, bipolar disorder or any other mental disorder) were excluded from the study.

\subsection{Tools and techniques}

The nature of the study was fully explained to the study subjects to obtain their written informed consent prior to participation in the study and they were reassured that their data would be kept confidential. At first contact i.e., during baseline ( $<16$ th week), pre-pregnancy weight (or weight at first antenatal visit) was recorded from their medical records and height was measured using standardised stadiometer. Using height and pre-pregnancy weight, pre-pregnancy BMI was computed. According to the Asian-Indians, BMI-cut off, ${ }^{26}$ subjects were classified into normal weight $\left(\mathrm{BMI}=18-22.9 \mathrm{~kg} / \mathrm{m}^{2}\right)$, overweight $(\mathrm{BMI}=$ $\left.23-24.9 \mathrm{~kg} / \mathrm{m}^{2}\right)$ and obese $\left(\mathrm{BMI}=>25 \mathrm{~kg} / \mathrm{m}^{2}\right)$.

\subsubsection{Collection of socio-demographic and obstetric history information}

A structured and standardised questionnaire was developed for in- person interview with subjects. Information about their age, family background, education, occupational exposure and obstetric history (parity, gravidity, abortion/miscarriage) were collected from subjects during their interview session at baseline ( $\leq 16$ th week of pregnancy).

\subsubsection{Screening of antenatal depression}

To ascertain the possibility of depression among the pregnant women, Edinburg Postnatal Depression Scale (EPDS) was used. EPDS is a 10 -item, self-administered scale, originally designed to identify women at risk for postpartum depression, but also later used for depression in pregnancy. ${ }^{27-32}$ It has been widely used in the Indian settings for assessing prenatal and postnatal depression. ${ }^{33,34}$ The EPDS comprises of 10 questions that access information about the respondent's mood and depressive symptoms during the 7 days preceding its administration. The responses were then coded from 0 to 3 ; higher scores meant possibility of emotional distress. Items 1, 2 and 4 were scored 0 for the top most response and 3 for the bottom most, while items 3, 5-10 were scored 3 for the top most response and 0 for the bottom most one exactly as given in the scale. Individual scores for each item were added to give a summed figure. Minimum score was 0 and maximum was 30 . Women scoring above 12 or 13 are likely to be suffering from depression. ${ }^{27,28}$ All the subjects were screened for depression at baseline i.e., $\leq 16^{\text {th }}$ week of pregnancy and to assess the risk of antenatal depression during different time intervals of pregnancy, subjects were followed up and screened on regular basis during 18 th -20 th week (midterm) and $\geq 32$ nd week (end-line) of pregnancy.

\subsection{Ethical approval}

The present study has been approved by the Ethics Committee of Institute of Home Economics (IHE/2018/1139), Delhi University, India. All the interested subjects were made to sign a written consent form. Only those, who gave their written consent to participate in study, were enrolled as study subjects.

\subsection{Data analysis}

SPSS (Statistical Package for Social Sciences), version 25 was used for statistical analysis of current study. Numerical characteristics were summarized as mean \pm standard deviation. Categorical variables were summarized using frequencies and percentages. Independent samples $\mathrm{T}$ test was used to explore the difference of depression scores of subjects within different pre-pregnancy BMI categories at different time intervals throughout the pregnancy. The level of significance was set at $<5 \%$.

\section{Results}

A total of 186 participants were recruited initially at baseline $(\leq 16$ th week) after appropriate screening according to pre-determined inclusion and exclusion criteria (section-2.1). According to the Asian Indians cut off, ${ }^{26} 60$ subjects were classified as normal weight (18.5-22.9 $\mathrm{kg} / \mathrm{m}^{2}$ ) whereas 58 and 68 subjects belonged to overweight (23-24.9 $\left.\mathrm{kg} / \mathrm{m}^{2}\right)$ and obese $\left(\geq 25 \mathrm{~kg} / \mathrm{m}^{2}\right)$ category respectively based upon their pre-pregnancy BMI. (Table: 1 ).

\subsection{Socio-demographic characteristics}

Data indicated that subjects were affluent and well educated. Although, half of the subjects had attained graduate or postgraduate/ higher degree, however, nearly half of them were homemakers. Among normal weight category, majority of respondents were $<30$ years of age (mean age: $29.25 \pm 2.43$ years) whereas overweight (mean age: $29.93 \pm$ 2.58 years) and obese category (mean:30.85 \pm 3.40 years) women had higher mean age with $51 \%$ subjects above 30 years of age. Socioeconomic status of subjects was classified using B.G Prasad's socioeconomic scale which is applicable to both urban and rural areas. ${ }^{35}$ In 
Table: 1

Maternal Anthropometric Characteristics for different categories of PrePregnancy Body Mass Index (BMI).

\begin{tabular}{|c|c|c|c|c|}
\hline \multirow[t]{2}{*}{ Characteristics } & \multicolumn{4}{|c|}{ Pre-pregnancy Body Mass Index (BMI) Category } \\
\hline & $\begin{array}{l}\text { Normal weight } \\
\mathrm{n}=60\end{array}$ & $\begin{array}{l}\text { Overweight } \mathrm{n} \\
=58\end{array}$ & $\begin{array}{l}\text { Obese } n= \\
68\end{array}$ & $\begin{array}{l}\text { TOTAL } \mathrm{N}= \\
186\end{array}$ \\
\hline \multicolumn{5}{|c|}{ Mean Height $(\mathrm{cm})$} \\
\hline & $160.60 \pm 4.69$ & $158.91 \pm 6.6$ & $\begin{array}{l}158.80 \pm \\
5.84\end{array}$ & $\begin{array}{l}159.64 \pm \\
5.75\end{array}$ \\
\hline \multicolumn{5}{|c|}{ Mean Pre-Pregnancy Weight (kg) } \\
\hline & $54.60 \pm 4.41$ & $60.28 \pm 5.21$ & $\begin{array}{l}73.67 \pm \\
10.56\end{array}$ & $\begin{array}{l}64.63 \pm \\
11.68\end{array}$ \\
\hline \multicolumn{5}{|c|}{ Mean Body Mass Index (BMI) (kg/m²) } \\
\hline & $21.2 \pm 1.40$ & $23.86 \pm 0.56$ & $\begin{array}{l}29.26 \pm \\
3.57\end{array}$ & $\begin{array}{l}25.42 \pm \\
4.39\end{array}$ \\
\hline
\end{tabular}

present study, data obtained from interview records showed that all subjects belong to the upper income group. Majority of the study subjects were found to be primiparous. Past obstetric history indicated abortion among normal weight (11.7\%), overweight (6.9\%) and obese (14.7\%) subjects.

Table 2 summarizes details of subject recruitment and drop outs. Out of total 60 normal weight subjects, 56 subjects were followed till endline. In case of overweight category, out of total subjects $(n=58), 50$ and 48 were followed till midterm and 48 up to end-line respectively. In case of obese subjects $(n=68), 57$ subjects were followed up till end-line and required data was collected from them.

\subsection{Prevalence and magnitude of antenatal depression across different pre-pregnancy BMI classification}

Data from EPDS indicated high prevalence of AD among the subjects. Almost $38 \%-40 \%$ of subjects showed signs of depression during the different stages of pregnancy (Fig. 1). In all the three weight categories, there was an increase in prevalence of $\mathrm{AD}$ towards the end of pregnancy. Further, data also indicated that higher proportions of depressed subjects were observed among obese category throughout pregnancy.

Fig. 2 represents the change in mean scores of $\mathrm{AD}$ obtained among the subjects of different pre-pregnancy BMI categories over different time interval throughout pregnancy. It was observed that the mean EPDS scores increased with progress in pregnancy. Obese subjects scored highest on depression scale during all three phases: baseline (12.03), midterm (11.69) and end-line (12) as compare to normal weight $(9.72,10.16,11.2)$ and overweight subjects $(9.86,10.4,10.62)$. Thus, increase in EPDS score was observed among all the subjects: normal weight and overweight/obese category as pregnancy progressed further. Independent samples T-tests indicated significant difference in the antenatal depression scores between overweight, obese subjects and normal weight, obese subjects at baseline phase of pregnancy $(\leq 16$ th week) (Table 3).

Table: 2

Number of Drop outs and Spontaneous Abortion among different Pre-pregnancy BMI category subjects at Baseline, Midterm and End-line.

\begin{tabular}{|c|c|c|c|c|c|c|}
\hline \multirow[t]{2}{*}{ Time Interval during Pregnancy } & \multicolumn{2}{|c|}{$\begin{array}{l}\text { Normal } \\
\text { weight ( } \mathrm{n}= \\
60)\end{array}$} & \multicolumn{2}{|c|}{$\begin{array}{l}\text { Overweight (n } \\
=58 \text { ) }\end{array}$} & \multicolumn{2}{|c|}{$\begin{array}{l}\text { Obese }(n= \\
68)\end{array}$} \\
\hline & DO & SA & DO & SA & DO & SA \\
\hline Baseline & 3 & 1 & 2 & 6 & 3 & 7 \\
\hline Midline & 0 & 0 & 2 & 0 & 1 & 0 \\
\hline End-line & 0 & 0 & 0 & 0 & 0 & 0 \\
\hline TOTAL SUBJECTS & 56 & & 48 & & 57 & \\
\hline
\end{tabular}

Abbreviations: DO-Drop Outs, SA-Spontaneous Abortion.

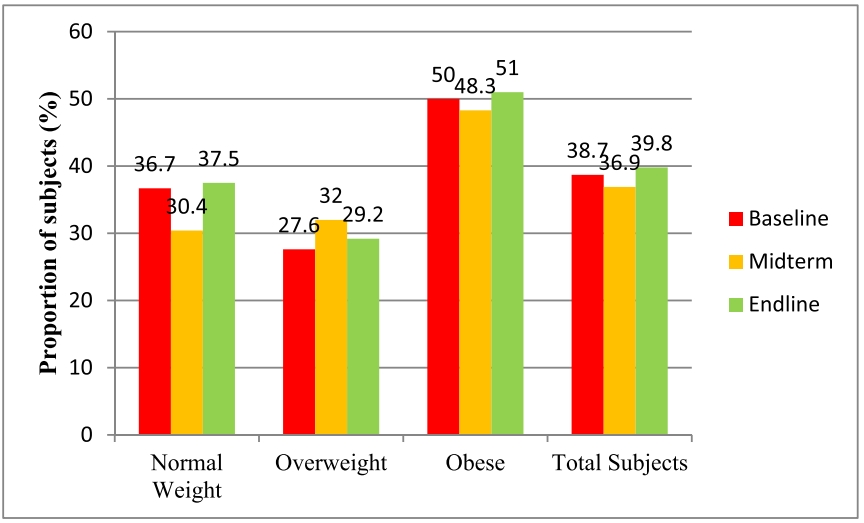

Fig. 1. Prevalence of Antenatal Depression across different Pre-pregnancy BMI category during Baseline, Midterm and End-line.

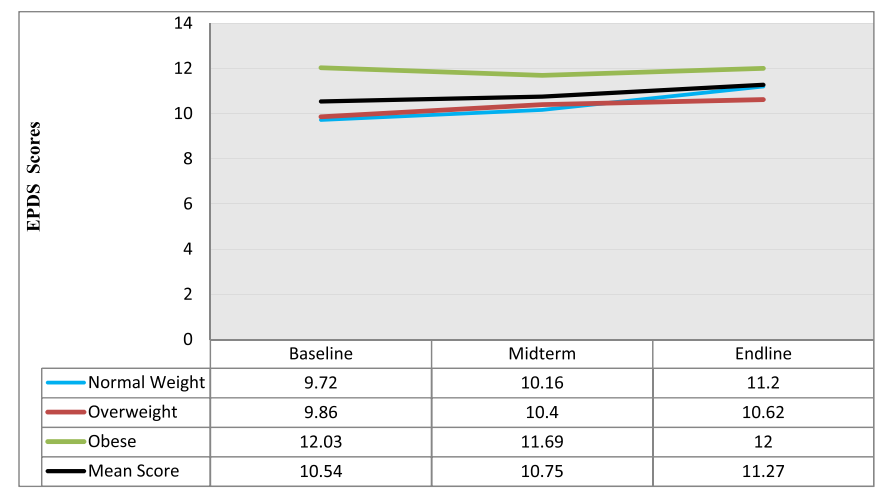

Fig. 2. Change in EPDS scores of antenatal depression over different time interval throughout pregnancy (baseline, midterm, end-line).

Table: 3

Comparison of depression scores among different pre-pregnancy BMI groups using Independent Sample T- Test (2-tail) at Baseline, Midterm and End-line.

\begin{tabular}{llll}
\hline Pre-pregnancy BMI category & Baseline & Midterm & End-Line \\
\hline NW, OW & & & \\
t-value & -0.1569 & -0.3103 & 0.7170 \\
p-value & 0.8755 & 0.7569 & 0.4749 \\
NW, OB & & & \\
t-value & -2.5868 & -1.848 & -0.99848 \\
p-value & $0.0108^{*}$ & 0.067 & 0.3202 \\
OW,OB & & & \\
t-value & -2.500 & 1.641 & -1.929 \\
p-value & $0.0137^{*}$ & 0.1036 & 0.056 \\
\hline
\end{tabular}

* Significant at $<0.05$. Abbreviations: BMI-Body Mass Index, OB-Obese, OWOverweight, NW: Normal Weight.

\section{Discussion}

Maternal and Child Health Programmes in developing countries are commonly focused upon improving the nutritional status and less attention is given to woman's emotional and mental health during and after pregnancy. ${ }^{36,37}$ Most of the existing data, research, and practice policies with regard to perinatal mental disorders lay emphasis on the postnatal period and there is less research related to depression during pregnancy.

In present study, nearly $40 \%$ of subjects screened positive on EPDS scale which is suggestive of a high probability of depression among all the respondents within different weight categories. There are few studies which have been conducted in other parts of India with 
concordant results. Two studies from Karnataka showed that $35.7 \%$ and $36.8 \%$ subjects respectively screened positive for prenatal depression ${ }^{15,38}$ whereas other studies have reported lower prevalence rates for depression of $26 \%$ in Jammu and Kashmir, ${ }^{36} 24.8 \%$ in Banglore, ${ }^{39}$ $16.3 \%$ in coastal south India, ${ }^{40} 12.3 \%$ in Bangalore ${ }^{41}$ and $9.18 \%$ in Navi Mumbai ${ }^{16}$ respectively. This discrepancy in prevalence rate of depression across different studies could be attributed to diversity in the socio-economic status and different scale used to measure depression. Moreover, in present study pregnant women were recruited irrespective of their poor obstetric history or presence of any obstetric complication which itself could pose a risk as a predictor for prenatal depression ${ }^{40}$ whereas in other studies, reportedly women either with poor obstetric history or obstetric/medical complication in the current pregnancy were excluded from participating in the study. ${ }^{36,38,39}$ The increased prevalence of prenatal depression towards the end of pregnancy in current study is consistent with a study conducted in Banglore ${ }^{39}$ where highest proportion of women were reported with possible depression during third trimester $(30.11 \%)$ compared to first trimester $(17.1 \%)$. This change in pattern of depression symptoms during pregnancy among the Indian women is another prominent finding. The increase in depression symptoms in present study from baseline towards the end of pregnancy could have resulted from increased psychological and physiological demands of advancing pregnancy ${ }^{38}$ or psychosocial adjustments to impending delivery.

Recently, another study conducted in Banglore ${ }^{38}$ explored the relationship between pre-pregnancy BMI and antenatal depression. The results showed antenatal depression to be more prevalent among normal weight category (56\%) than obese women $(32 \%)$ whereas according to available evidence from western countries, pre-pregnancy obese women are more likely to experience elevated depression symptoms compared to normal weight women, with intermediate risk for overweight women. ${ }^{18,42}$ This is in line with present study as among all three weight categories, higher proportion of obese subjects were found to be positive for depression and scored highest on EPDS scale throughout pregnancy compared to normal weight and overweight subjects. In addition to this, nearly half of obese subjects were found to be depressed from baseline to end-line during pregnancy. Similar findings were observed in cohort study conducted in Iran. ${ }^{42}$ Based on EPDS, it has been reported that $32.3 \%, 33.3 \%$ and $28.8 \%$ obese pregnant women screened positive for depression comparatively to normal weight women $(12.7 \%, 13.5 \%$, $10.2 \%$ ) during first, second and third trimester respectively. It was concluded that pre-pregnancy obese women are at a high risk of maternal depression during prenatal period. ${ }^{42}$ In addition to this, it has been well documented in past that obese pregnant women are at increased risk for an array of gestational complications ${ }^{43}$ and these risks may further get amplified with increase in maternal depression which could adversely affect birth outcome. ${ }^{18,44}$ Hence, it can be inferred that both pre-pregnancy obesity and antenatal depression can have co-morbid impact on maternal outcome, which, further makes obese pregnant women a high risk group compared to women with normal pre-pregnancy BMI. ${ }^{42}$

\section{Conclusion}

Results from the study indicated that obese women are likely to experience more symptoms of depression as compared to the women with lower BMI (normal weight, overweight) throughout pregnancy. Expanding the research in this area can provide valuable inputs to adopt a holistic approach to cater to pregnant women especially the ones with higher pre-pregnancy weight. Regular screening of antenatal depression and appropriate lifestyle related advice must be provided to pregnant women to ensure their healthy pregnancy. The present study has provided evidence for the hidden burden of $\mathrm{AD}$ and its association with prepregnancy BMI even among women of upper SES. Present endeavour can provide valuable impetus for the development of interventions aimed at addressing this major issue which has so far been neglected in
India.

\section{Strengths and limitations}

Our study lays emphasis on $\mathrm{AD}$ which has received less attention compared to postnatal depression globally. In our best knowledge, there is paucity in studies which have addressed this major issue of $\mathrm{AD}$ among Indian women with higher pre-pregnancy BMI. In order to ascertain the possibility of depression, EPDS scale with good psychometric properties was used to screen the subjects. The study had few limitations too. The findings of study cannot be extrapolated to pregnant women belonging to lower socio-economic status as there could be variations in psychosocial factors and standard of living. Current study includes the limited sample size of only 186 pregnant women recruited from antenatal clinics. Since, present endeavour is a part of ongoing study, further additions to the sample size and other relevant study parameters would strengthen the data and study.

\section{Financial support and sponsorship}

The first author has been awarded a University's Grant Commission's (UGC) Research Fellowship (UGC-Ref. No.: 12510) for present study which is a part of ongoing Ph.D. research work.

\section{Author's contributions}

Priyanka Arora was responsible for study conception, data collection, statistical analysis and drafting of the manuscript. Dr. Bani Tamber Aeri was responsible for planning of the study, drafting and finalising manuscript.

\section{Declaration of competing interest}

The authors claim no conflict of interest.

\section{Acknowledgement}

The authors acknowledge the financial assistance provided by the University Grant Commission, Government of India, under the Junior/ Senior Research Fellow Scheme which has been awarded to first author. We would like to extend our sincere thanks to the participants of study and staff of antenatal clinics in North-West Delhi for supporting us during data collection.

\section{References}

1 International Institute for Population Sciences (IIPS). National family health survey (NFHS-4), Mumbai, India. http://rchiips.org/nfhs/NFHS-4Reports/India.pdf; 20152016. Accessed March 10, 2020.

2 National family health survey (NFHS-3) 2005-06. Mumbai: International Institute for Population Sciences (IIPS) and Macro International. Available from: http://www. rchiips.org/nfhs/nfhs3.shtml; 2009. Accessed March 10, 2020.

3 Doherty D, Magann E, Francis J, Morrison J, Newnham J. Pre-pregnancy body mass index and pregnancy outcomes. Int J Gynecol Obstet. 2006;95(3):242-247.

4 Hoff G, Cai J, Okah F, Dew P. Pre-pregnancy overweight status between successive pregnancies and pregnancy outcomes. J Wom Health. 2009;18(9):1413-1417.

5 Kim S, Sharma A, Sappenfield W, Wilson H, Salihu H. Association of maternal body mass index, excessive weight gain, and gestational diabetes mellitus with large-forgestational-age births. Obstet Gynecol. 2014;123(4):737-744.

6 Yu Z, Han S, Zhu J, Sun X, Ji C, Guo X. Pre-pregnancy body mass index in relation to infant birth weight and offspring overweight/obesity: a systematic review and metaanalysis. PloS One. 2013;8(4), e61627.

$720 \%$ of depressed Indians are pregnant or new mums: nimhans study. Times of India. Available from: http://timesofindia.indiatimes.com/city/bengaluru/20-of-depress ed- Indians-are-pregnant-or-new-mums-Nimhans-study/articleshow/55252311.cms; 2016 November 5. Accessed March 10, 2020.

8 DiPietro JA. Psychological and psychophysiological considerations regarding the maternal-fetal relationship. Infant Child Dev. 2010;19:27-38.

9 Lee DT, Chan SS, Sahota DS, Yip AS, Tsui M, Chung TK. A prevalence study of antenatal depression among Chinese women. J Affect Disord. 2004;82(1):93-99.

10 Eastwood J, Ogbo F, Hendry A, Noble J, Page A. The impact of antenatal depression on perinatal outcomes in Australian women. PloS One. 2017;12(1), e0169907. 
11 Pajulo M, Savonlahti E, Sourander A, Helenius H, Piha J. Antenatal depression, substance dependency and social support. J Affect Disord. 2001;65(1):9-17.

12 Nasreen HE, Kabir ZN, Forsell Y, Edhborg M. Prevalence and associated factors of depressive and anxiety symptoms during pregnancy: a population-based study in rural Bangladesh. BMC Wom Health. 2011 Jun 2;11:22.

13 Biratu A, Haile D. Prevalence of antenatal depression and associated factors among pregnant women in Addis Ababa, Ethiopia: a cross-sectional study. Reprod Health. 2015;12:99.

14 Humayun A, Haider II , Imran N, Iqbal H, Humayun N. Antenatal depression and its predictors in Lahore, Pakistan. East Mediterr Health J. 2013;19(4):327-332.

15 Pai K, Shruthi H, Hulegar A, Sandeep R. Prevalence of antenatal depression and gender preference: a cross sectional study among Mangalore population, Karnataka, India. J Pharmaceut Biomed Sci. 2013;29:1011-1014.

16 Ajinkya S, Jadhav P, Srivastava N. Depression during pregnancy: prevalence and obstetric risk factors among pregnant women attending a tertiary care hospital in Navi Mumbai. Ind Psychiatr J. 2013;22(1):37.

17 Bogaerts AF, Devlieger R, Nuyts E, et al. Anxiety and depressed mood in obese pregnant women: a prospective controlled cohort study. Obes Facts. 2013;6(2): $152-164$.

18 Molyneaux E, Poston L, Ashurst-Williams S, Howard L. Obesity and mental disorders during pregnancy and postpartum. Obstet Gynecol. 2014;123(4):857-867.

19 Laraia B, Siega-Riz A, Dole N, London E. Pregravid weight is associated with prior dietary restraint and psychosocial factors during pregnancy. $J$ Obes. 2009;17(3): $550-558$.

20) Accortt E, Cheadle A, Dunkel Schetter C. Prenatal depression and adverse birth outcomes: an updated systematic review. Matern Child Health J. 2014;19(6): 1306-1337.

21 Szegda K, Markenson G, Bertone-Johnson E, Chasan-Taber L. Depression during pregnancy: a risk factor for adverse neonatal outcomes? A critical review of the literature. J Matern Fetal Neonatal Med. 2013;27(9):960-967.

22 O'Connor TG, Monk C, Fitelson EM. Practitioner review: maternal mood in pregnancy and child development-implications for child psychology and psychiatry. JCPP (J Child Psychol Psychiatry). 2014;55:99-111.

23 Kingston D, McDonald S, Austin M, Tough S. Association between prenatal and postnatal psychological distress and toddler cognitive development: a systematic review. PloS One. 2015;10(5), e0126929.

24 Stein A, Pearson R, Goodman S, et al. Effects of perinatal mental disorders on the fetus and child. Lancet. 2014;384(9956):1800-1819.

25 Luppino F, de Wit L, Bouvy P, et al. Overweight, obesity, and depression. Arch Gen Psychiatr. 2010;67(3):220.

26 Misra A, Nigam P, Hills A, et al. Consensus physical activity guidelines for asian Indians. Diabetes Technol Therapeut. 2012;14(1):83-98.

27 Srinivasan N, Murthy S, Singh AK, Upadhyay V, Mohan SK, Joshi A. Assessment of burden of depression during pregnancy among pregnant women residing in rural setting of Chennai. J Clin Diagn Res. 2015;9:8-12.
28 Cox J, Holden J, Sagovsky R. Detection of postnatal depression. Br J Psychiatry. 1987; 150(6):782-786

29 Wisner K, Parry B, Piontek C. Postpartum depression. N Engl J Med. 2002;347(3): 194-199.

30 Flynn H, Sexton M, Ratliff S, Porter K, Zivin K. Comparative performance of the edinburgh postnatal depression scale and the patient health questionnaire- 9 in pregnant and postpartum women seeking psychiatric services. Psychiatr Res. 2011; 187(1-2):130-134.

31 Murray D, Cox J. Screening for depression during pregnancy with the edinburgh depression scale (EDDS). J Reprod Infant Psychol. 1990;8(2):99-107.

32 Austin M, Hadzi-Pavlovic D, Saint K, Parker G. Antenatal screening for the prediction of postnatal depression: validation of a psychosocial Pregnancy Risk Questionnaire. Acta Psychiatr Scand. 2005;112(4):310-317.

33 Shenoy H, Remash K, Shenoy S. Prevalence and determinants of postnatal depression in a tertiary care teaching institute in Kerala, India. Int $J$ Reprod Contracept Obstet Gynecol. 2019;8(9):3757.

34 Suresh M, Ramesh K, Dilip G, Bhimrao D. A cross sectional hospital based study of antepartum depression and its' risk factors. Int J Med Publ Health. 2018;8(4): $158-162$.

35 Khairnar M, Wadgave U, Shimpi P. Updated BG Prasad socioeconomic classification for 2016. J Indian Assoc Public Health Dent. 2016;14(4):469.

36 Rahman A, Patel V, Maselko J, Kirkwood B. The neglected ' $m$ ' in MCH programmes why mental health of mothers is important for child nutrition. Trop Med Int Health. 2008;13(4):579-583.

37 Bowen A, Muhajarine N. Antenatal depression. Can Nurse. 2006;102:26-30.

38 Sheeba B, Nath A, Metgud C, et al. Prenatal depression and its associated risk factors among pregnant women in Bangalore: a hospital based prevalence study. Front. Public Health. 2019;7:108.

39 Maheshwari M, Divakar V. A cross sectional study on mental health status of pregnant women at urban health centre of Bangalore, India. Int $J$ Community Med Public Health. 2016;3:897-899.

40 George C, Lalitha A, Antony A, Jacob K. Antenatal depression in costal South India: prevalence and risk factors in the community. Int J Soc Psychiatr. 2015;62:141-147.

41 Bavle A, Chandahalli A, Phatak A, Rangaiah N, Kuthandahalli S, Nagendra P. Antenatal depression in a tertiary care hospital. Indian J Psychol Med. 2016;38(1):31.

42 Salehi-Pourmehr H, Mohammad-Alizadeh S, Jafarilar-Agdam N, Rafiee S, FarshbafKhalili A. The association between pre-pregnancy obesity and screening results of depression for all trimesters of pregnancy, postpartum and 1 year after birth: a cohort study. J Perinat Med. 2018;46(1):87-95.

43 Lynch C, Sexton D, Hession M, Morrison J. Obesity and mode of delivery in primigravid and multigravid women. Am J Perinatol. 2008;25(3):163-167.

44 Fekadu Dadi A, Miller E, Mwanri L. Antenatal depression and its association with adverse birth outcomes in low and middle-income countries: a systematic review and meta-analysis. PloS One. 2020;15(1), e0227323. 